\title{
The commitment Challenger Tour players make as junior athletes
}

\author{
Edward Horne $^{a} \&$ Matthew Haugen ${ }^{a}$ \\ ${ }^{a}$ University of Illinois at Urbana-Champaign, Champaign, IL, United States.
}

\section{ABSTRACT}

Professional tennis players competing at the Challenger Tour level were interviewed to further understanding of how professionals perceive their advancement. Results showed athletes make extensive commitments to facilitate advancement. Commitments that likely impact their career options after tennis. Implications and suggestions for moving forward are discussed.

\author{
Key words: Advancement, \\ career development, \\ commitment, professional \\ players. \\ Received: 11 June 2019 \\ Accepted: 08 August 2019 \\ Corresponding author: Edward \\ Horne, University of Illinois at \\ Urbana-Champaign, \\ Champaign, IL, United States. \\ Email: horne3@illinois.edu
}

\section{INTRODUCTION}

Sport plays a prominent role in society. Today, thousands of children participate in sport programming with the ambition of becoming a professional athlete. The increasing popularity of sport has contributed to the development of a youth sport industry worth an estimated $\$ 15$ billion (Gregory, 2017). This booming industry has impacted the youth sport experience, causing aspiring professional athletes to spend increasing amounts of their childhood in the sport environment (Brustad, 2011). By spending more time training for their respective sports, athletes are therefore likely spending less time pursuing other activities. Yet, little research exists that examines how athletes advance from youth to professional sport from those who have done so successfully. The purpose of the current study then, was to examine professional tennis players' perception of their advancement and how the extent of their commitment may impact their post-sport careers.

\section{LITERATURE REVIEW}

The study was guided by Green's (2005) essential tasks for sport development. Specifically, the study was guided by the concept of commitment (a key underlying concept of retention), and the essential task of advancement.
Commitment was used as it can explain the steps taken to manage their elite development. Our current understanding of athlete advancement is lacking, which is concerning as advancement is not guaranteed (Green, 2005). This study will therefore contribute to a subject area lacking scientific study.

Research investigating athletes' retirement from sport shows they are often ill-prepared (Stronach \& Adair, 2010). This is concerning as most professional athletes will need to transition directly into another career post-sport. This is especially true of professional tennis players, as research has shown only those in the top 100 experience financial independence (Brouwers, Sotiriadou, \& De Bosscher, 2015a). Most professional tennis players, therefore, struggle to earn a living.

Our understanding of athletes' transition out of sport is limited as retirement is often viewed as a single event (Stambulova \& Roessler, 2010). Interventions for improving this experience therefore often fail to account for the athlete's entire journey. This is problematic as athletes make commitments in youth that may impact their post-sport career preparedness. The current study set out to answer the following research questions:

1. What commitments do current professional tennis players believe are necessary for advancement? 
2. How does professional tennis players' commitment to their sport impact their personal development?

\section{METHOD}

A narrative inquiry approach (Clandinan, 2006) was adopted to explore participants' entire journey. Six male participants were recruited from a Challenger Tour tournament in the Midwest, United States. Participants rankings ranged between 200-600. Below, Table 1 illustrates Crespo and colleagues' (2003) breakdown of tournament and ranking levels.

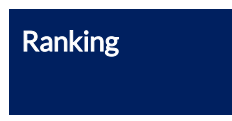

Tournament Level

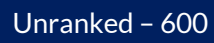

Qualifying Futures

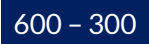

Main Draw Futures

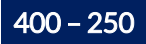

Qualifying Challenger Events

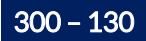

Qualifying Grand Slam Events

$250-100$

Main Draw Challenger Events/Qualifying ATP Tour Events

$130-1$

Main Draw of ATP Tour Events

$110-1$

Main Draw of Grand Slams

Table 1. Breakdown of rankings required at each tournament level.

Interviews were coded separately by each researcher. A priori, thematic coding technique was adopted as recommended by Saldaña (2014). Any discrepancies in researchers' analyses were discussed until consensus was achieved.

\section{RESULTS}

Players' advancement appeared to depend on a relentless commitment to tennis. Participants relocated as children for tennis, usually without their families, and reduced time in traditional schools. This commitment may, therefore, have impacted their ability to acquire additional qualifications and life-skills, likely diminishing their post-tennis career opportunities. Three themes emerged: Commitment, retention, and advancement. Findings are presented in chronological form using Côté's (1999) Developmental Model of Sport Participation.

Specialization Phase (age 13-15)

Commitment. By age 13 professional athletes had begun or were in the process of increasing their dedication to tennis. This meant leaving traditional school settings, relocating, and/or dropping other sports. As Player 1 from Spain described:

I began to make sacrifices for my tennis around age 13/14. I attended a school specifically designed for kids playing sport as seriously as I was. At this school I was able to spend 4 hours a day training both on and off the court.

Player 5 from South Africa also adjusted his scheduling at a similar age for his tennis: "By 14 I shut down my participation in other sports so I could practice 5 times a week." Few participants discussed retention during this phase. They also saw their increasing commitment to tennis as key to enabling advancement.

Investment Phase (15-18)

Commitment. At this stage, participants began to grapple with balancing their tennis and education. Most felt compelled by to structure their schooling around their tennis, as Player 2 from the US elicited:

If I wanted to play at a high level in college while staying in high-school that's what it was going to take. Classes at 6:30a.m., so I could leave school early and drive the hour or so to practice where I would often be till 9p.m.

Advancement. Players also discussed being short of viable advancement options. For instance, Player 4 from the US stated: "My family couldn't afford for me to stay home and work with my coach as much as I would need. So relocating and accepting the academy's scholarship was my only option." Player 5 had a similar experience: "I got the opportunity to move from South Africa to Boston. My parents couldn't afford much so if I wanted to give it a go then this was it."

US College or Professional Tour (18+)

Advancement. When transitioning into senior tennis, participants had to choose between going to college or turning professional. Of the six interviewees, five initially chose college tennis, as Player 6 from the US explained: "I knew to break-even I'd need to be around 300 and I wasn't even close. My family could only fund me for a year, so college was a no-brainer." Player 3 , also from the US, saw it as an opportunity to delay the risks of turning professional: "In college I could mature, train and compete with good players at no expense. Then I could have another crack at going professional." Player 1 , the only player to transition directly into pro tennis explained: "I did think about college, but 
decided against it. I had been a top junior player in Spain so thought I would make it."

Professional Career

Retention. Many players appeared to struggle with life on the professional tour. Player 5 mentioned: "I am away from friends and family for 8 to 9 months a year. I've been traveling alone these last two months. I will certainly sit down at the end of the year and see how much longer I can do this." Only two players contemplated life after tennis. For example, Player 1 described:

There are days I want to quit, especially after a run of bad tournaments. But what else am I going to do? All I have is a diploma from an academy. That's fine if you want to work in a supermarket, but that is not my goal.

The lack of alternatives to tennis was being addressed by Player 5, who said: "I'm finishing my degree online. Rather than just sit in the hotel room for hours, I study. I'd ideally like to stay in tennis, but I don't see myself as a career coach."

\section{DISCUSSION}

As professional coaches and tennis experts, players relocating and restructuring their schooling to facilitate advancement will not come as a great surprise. However, it is important to recognize the impact extensive levels of commitment may have on athletes' careers after tennis. This matters as most professional tennis players will need to be ready to transition into a new career, which they appear unprepared for. The findings of the current study therefore contribute to our understanding of retirement and demonstrate the need to account for athletes' entire journey.

Findings also suggest reaching the professional level of tennis may depend on players' willingness to prioritize tennis above all else. Fortunately, the existence of the US collegiate tennis system provides players with an option for continuing education, while proving a viable avenue to professional tennis. However, while retiring with a degree is certainly advantageous, a lack of relevant work experience would leave players eligible for little more than entry-level positions.

It is unrealistic to think the required levels of dedication and commitment will ever abate. To the contrary, moving forward, one would expect even greater dedication and commitment will be required. It is not the authors' expectation, or ambition to reinvent the wheel. Rather, we hope to raise greater awareness of this issue, with the long-term objective of developing and implementing measures that equip players with greater post-tennis career possibilities. Especially, as the post-career support has been found to rank low on tennis experts' list of policy concerns (Brouwers, Sotiriadou, \& De Bosscher, 2015b).

Further examination is clearly warranted. Ensuring youth players and their support teams are aware of the need to prepare for a career after tennis should be the first step taken. Future research should then look to determine what measures are feasible in the current tennis system/environment.

\section{REFERENCES}

Brouwers, J., Sotiriadou, P. \& De Bosscher, V. (2015a). An examination of the stakeholders and elite athlete development pathways in tennis. European Sport Management Quarterly, 15(4), 454-477.

Brouwers, J., Sotiriadou, P., \& De Bosscher, V. (2015b). Sportspecific policies and factors that influence international success: The case of tennis. Sport Management Review, 18(3), 343-358.

Brustad, R. J. (2011). Enhancing Coach-Parent Relationships in Youth Sports: Increasing Harmony and Minimizing Hassle: A Commentary. International Journal of Sports Science \& Coaching, 6(1), 33-35, https://doi.org/10.1260/1747-9541.6.1.33

Clandinan, D. J. (2006). Narrative inquiry: A methodology for studying lived experience. Research Studies in Music Education, 271), 44-54, https://doi.org/10.1177/1321103X060270010301

Côté, J. (1999). The influence of the family in the development of talent in sport. The Sport Psychologist, 13(4), 395-417, https://doi.org/10.1123/tsp.13.4.395

Crespo, M., Reid, M., Miley, D., \& Atienza, F. (2003). The relationship between professional tournament structure on the national level and success in men's professional tennis. Journal of Science and Medicine in Sport, 6(1), 313, https://doi.org/10.1016/S1440-2440(03)80003-8

Green, B. C. (2005). Building sport programs to optimize athlete recruitment, retention, and transition: Toward a normative theory of sport development. Journal of Sport Management, 193), 233-253, https://doi.org/10.1123/jsm.19.3.233

Gregory, S. (2017, August 24). How kid's sports became a $\$ 15$ billion industry. Retrieved from http://time.com/4913687/how-kids-sports-became-15billion-industry/.

Saldaña, J. (2014). Thinking qualitatively: Methods of mind. Los Angeles, CA: Sage.

Stronach, M. M., \& Adair, D. (2010). Lords of the square ring: Future capital and career transition issues for elite indigenous Australian boxers. Cosmopolitan Civil Societies: An Interdisciplinary Journal, 2(2), 46-70, https://doi.org/10.5130/ccs.v2i2.1512

Taylor, J. L. (2013). The power of resilience: A theoretical model to empower, encourage and retain teachers. The Qualitative Report, 18(35), 1-25. 
RECOMMENDED ITF TENNIS ACADEMY CONTENT (CLICK BELOW)

\section{ITF Academy}

Copyright (c) 2019 Edward Horne \& Matthew Haugen

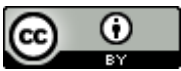

This text is under a Creative Commons BY 4.0 license

You are free to Share - copy and redistribute the material in any medium or format - and Adapt the content - remix, transform, and build upon the material for any purpose, even commercially under the following terms:

Attribution: You must give appropriate credit, provide a link to the license, and indicate if changes were made. You may do so in any reasonable manner, but not in any way that suggests the

licensor endorses you or your use.

CCBY4.0 license terms summary CCBY4.0license terms 